\title{
ANALISIS DINAMIK SUDUT DEFLEKSI PADA MODEL VIBRASI DAWAI
}

\author{
1'Imam Mufid, ${ }^{2}$ Ari Kusumastuti, ${ }^{3}$ Fachrur Rozi
}

\begin{abstract}
1Jurusan Matematika, Universitas Islam Negeri Maulana Malik Ibrahim Malang 2jurusan Matematika, Universitas Islam Negeri Maulana Malik Ibrahim Malang 3jurusan Matematika, Universitas Islam Negeri Maulana Malik Ibrahim Malang
\end{abstract}

Email: imam.mufid@outlook.com

\begin{abstract}
ABSTRAK
Model McKenna menggambarkan gerak vertikal dawai dan gerak torsi pada balok yang digantungnya. Sudut defleksi merupakan sudut yang terbentuk pada gerak torsi. Dengan mengasumsikan bahwa dawai tidak pernah kehilangan ketegangan, maka diperoleh sistem tak berpasangan yang dapat dianalisis secara terpisah. Pada artikel ini ditunjukkan pengaruh faktor eksternal terhadap kestabilan dan perilaku dari model sudut defleksi. Untuk mengetahui kestabilan dan perilaku dari sudut defleksi digunakan analisis sistem dinamik. Berdasarkan hasil analisis, dengan menambahkan massa dari balok yang digantung akan diperoleh tiga solusi yang berbeda berdasarkan nilai eigennya. Faktor eksternal memiliki pengaruh terhadap kestabilan dan perubahan besarnya sudut yang terbentuk pada model sudut defleksi, hal ini disebabkan setelah ditambahkan faktor ekstern medan vektor dari model bergerak secara tidak beraturan atau bersifat chaotic.
\end{abstract}

Kata kunci: sistem dinamik, model McKenna, sistem tak homogen, sudut defleksi

\section{ABSTRACT}

The McKenna is model describes vertical motion on string and torque motion on the beam that is hunged by string. Deflection is an angle formed at the torque motion. Assuming that string never lost tension, So an unpaired system that can be analyzed separately is obtained. In this article we show the influence of external factor on stability and behaviour of deflection angle of the models. To know the stability and behaviour of the deflection angle model, we used dynamic system analysis. Based on the analysis, by adding mass of the beam which is suspended will be obtained three different solutions based on it's eigenvalues. External factors have an influence on the stability and evolution of angle formed on the deflection angle models, this is due to external factors after adding the vector field of the model moves irregularly or is chaotic.

Keywords: dynamical system, McKenna model, nonhomogeneous system, deflection angle

\section{PENDAHULUAN}

Banyak fenomena alam yang terjadi yang dapat dianalisis dengan menggunakan model matematika, seperti getaran dan gelombang. Vibrasi merupakan fenomena alam yang sering terjadi. Sehingga akan memberikan manfaat yang besar jika memperlajari fenomena vibrasi ini. Salah satu model matematiika yang menggambarkan vibrasi adalah model McKenna yang merepresentasikan sistem gerak yang terdiri dari gerak vertikal dan gerak torsi.

Berikut adalah model McKenna yang menggambarkan dinamika pergerakan torsi vertikal yang dinyatakan dalam: $\ddot{\theta}=\frac{3 K \cos (\theta)}{m l}$ $\left[(y-l \sin (\theta))^{+}-(y+l \sin (\theta))^{+}\right]-\delta_{1} \dot{\theta}+f(t)$ dan $\ddot{y}=\frac{-K}{m}\left[(y-l \sin (\theta))^{+}+(y+l \sin (\theta))^{+}\right]-$ $\delta_{2} \dot{y}+g$, dengan $\theta(t)$ merupakan sudut dari horizontal pada dawai pada waktu tertentu yang disebut dengan sudut defleksi. Sedangkan $y(t)$ menyatakan dinamika pergerakan vertikal dawai. Sudut defleksi pada skripsi ini menggambarkan gerak torsi dari dawai yang dibebani balok. Model dari sudut defleksi adalah salah satu model dinamik karena modelnya bergantung waktu dan dapat merepresentasikan skenario yang dapat berubah sepanjang waktu. Tujuan dari analisis dinamik adalah untuk menilai perilaku struktural dalam berbagai beban setiap waktu.

Berdasarkan teorema Hartman-Grobman, perilaku dari persamaan tak linier ekuivalen dengan persamaan hasil linierisasinya di sekitar titik kesetimbangan jika titik tetap tersebut hyperbolic. Titik kesetimbangan dikatakan hyperbolic jika nilai eigen dari hasil linierisasi di sekitar titik tersebut memiliki bagian real tak nol [1]. Karena model McKenna adalah persamaan diferensial tak linier, maka untuk dapat menganalisis model tersebut dilakukan pendekatan dengan melinierisasi model tersebut disekitar titik kesetimbangannya. 
Artikel ini merupakan upaya ilmiah untuk menganalisis perilaku dari perubahan sudut defleksi pada vibrasi dawai dalam kerangka penelitian pengembangan. skripsi ini dilakukan analisis sistem dinamik terhadap model tersebut, sehingga dapat diketahui respon yang terjadi dengan berbagai parameter yang diberikan dan juga dapat diketahui seberapa besar pengaruh dari faktor eksternal.

\section{KAJIAN TEORI}

\section{Linierisasi}

Fungsi $f\left(x_{1}, x_{2}\right)$ dapat diekspansi dengan menggunakan deret Taylor di sekitar titik kesetimbangan $\left(x_{10}, x_{20}\right)$, sebagai berikut:

$$
\begin{gathered}
f\left(x_{1}, x_{2}\right)=f\left(x_{10}, x_{20}\right)+\left.\frac{\partial f}{\partial x_{1}}\right|_{\substack{x_{1}=x_{10} \\
x_{2}=x_{20}}} \cdot\left(x_{1}-x_{10}\right)+ \\
\left.\frac{\partial f}{\partial x_{2}}\right|_{\substack{x_{1}=x_{10} \\
x_{2}=x_{20}}} \cdot\left(x_{2}-x_{20}\right)+\frac{1}{2 !}\left(\left.\frac{\partial^{2} f}{\partial x_{1}{ }^{2}}\right|_{\substack{x_{1}=x_{10} \\
x_{2}=x_{20}}} .\right. \\
\left(x_{1}-x_{10}\right)+\left.\frac{\partial^{2} f}{\partial x_{2}{ }^{2}}\right|_{\substack{x_{1}=x_{10} \\
x_{2}=x_{20}}} \cdot\left(x_{2}-x_{20}\right)^{2}+ \\
\left.\left.\frac{\partial^{2} f}{\partial x_{1} \partial x_{2}}\right|_{\substack{x_{1}=x_{10} \\
x_{2}=x_{20}}} \cdot\left(x_{1}-x_{10}\right)\left(x_{2}-x_{20}\right)\right)+\cdots
\end{gathered}
$$

\section{Sistem Linier}

Pada dasarnya setiap persamaan diferensial orde $n$ dapat diubah menjadi sistem dengan $n$ buah persamaan. Adapun contoh sistem linier adalah sebagai berikut. Diberikan persamaan diferensial linier orde dua:

$$
\ddot{x}=-k x-b \dot{x}
$$

Misal $x_{1}=x$ dan $x_{2}=\dot{x}$, sehingga persamaan (1) dapat ditulis sebagai sistem persamaan diferensial linier orde satu.

$$
\begin{aligned}
& \dot{x}_{1}=x_{2} \\
& \dot{x}_{2}=-k x_{1}-b x_{2}
\end{aligned}
$$

[2].

Diberikan sistem sebagi berikut:

$$
\dot{x}=\boldsymbol{A x}
$$

Misal matriks $\boldsymbol{A}$ dari sistem (3) merupakan matriks berukuran $2 \times 2$ dan jika sistem (3) mempunyai nilai-nilai eigen yang berbeda, maka solusi umum sistem (3) adalah:

$$
\boldsymbol{x}(t)=C_{1} \boldsymbol{v} e^{\lambda_{1} t}+C_{2} \boldsymbol{u} e^{\lambda_{2} t}
$$

dengan $\boldsymbol{v}$ dan $\boldsymbol{u}$ adalah vektor-vektor eigen yang bersesuaian dengan nilai eigen $\lambda_{1}$ dan $\lambda_{2}$ [3].

Jika persamaan karakteristik (3) mempunyai akar kembar $\lambda_{1,2}=\lambda$, dan diperoleh:

(a) Dua vektor eigen, maka solusinya adalah:

$$
\boldsymbol{x}(t)=C_{1} \boldsymbol{v} e^{\lambda_{1} t}+C_{2} \boldsymbol{u} e^{\lambda_{1} t}
$$

(b) Satu vektor eigen, maka solusinya adalah:

$$
\boldsymbol{x}(t)=C_{1} \boldsymbol{v} e^{\lambda t}+C_{2}(\boldsymbol{v} t-\boldsymbol{w}) e^{\lambda t}
$$

dengan $(\boldsymbol{A}-\boldsymbol{I}) \boldsymbol{w}=\boldsymbol{v}[3]$.

Jika $\lambda_{1,2}=a \pm i b$ merupakan akar kompleks dari (3) dan $\boldsymbol{v}_{1,2}=\boldsymbol{u} \pm \boldsymbol{i w}$ adalah vektor eigen yang bersesuaian, maka:

$$
\begin{gathered}
\boldsymbol{x}(t)=e^{a t} C_{1}(\cos (b t) \boldsymbol{u}-\sin (b t) \boldsymbol{w})+ \\
e^{a t} C_{2}(\sin (b t) \boldsymbol{u}+\cos (b t) \boldsymbol{w})
\end{gathered}
$$

adalah masing-masing solusi dari $\dot{\boldsymbol{x}}=\boldsymbol{A} \boldsymbol{x}[2]$.

\section{Sistem Tak Homogen}

Sistem persamaan diferensial linier tak homogen secara umum dapat dituliskan sebagai:

$$
\dot{\boldsymbol{x}}=\boldsymbol{A}(t) \boldsymbol{x}+\boldsymbol{g}(t)
$$

Solusi $\boldsymbol{x}(t)$ dari persamaan diferensial linier tak homogen (8) dengan kondisi awal $\boldsymbol{x}(0)=\boldsymbol{x}_{0}$, dapat ditulis sebagai:

$$
\boldsymbol{x}(t)=e^{A t}\left(\boldsymbol{x}_{0}+\int_{\mathbf{0}}^{t} e^{A t} \boldsymbol{g}(s) d s\right)
$$

\section{Model McKenna}

Penurunan persamaan vibrasi merambat pada dawai mengikuti energi potensial dari dawai dengan konstanta spring $K$ dan merentang sejauh $x$ dari titik kesetimbangan. Sehingga diperoleh:

$$
E P_{\text {dawai }}=\int K x d x=\frac{1}{2} K x^{2}
$$

Dengan demikian energi potensial total adalah:

$$
\begin{aligned}
E P_{\text {dawai total }}= & \frac{1}{2} K\left(\left((y-l \sin (\theta))^{+}\right)^{2}\right. \\
& \left.-\left((y+l \sin (\theta))^{+}\right)^{2}\right)
\end{aligned}
$$


Energi potensial $E P_{\text {balok }}$ karena beban dari balok dengan massa $m$ yang mengalami perubahan posisi ke bawah dari titik kesetimbangan dengan jarak $y$, diberikan sebagai berikut:

$$
E P_{\text {balok }}=-m y g
$$

Dimana $g$ adalah gaya gravitasi. Sehingga diperoleh energi potensial model dari dawai dan balok yaitu:

$$
\begin{aligned}
E P_{m} & =E P_{\text {dawai total }}+E P_{\text {balok }} \\
E P_{m} & =\frac{K}{2}\left(\left[(y-l \sin (\theta))^{+}\right]^{2}-\left[(y+l \sin (\theta))^{+}\right]^{2}\right) \\
& -m y g
\end{aligned}
$$

Kemudian dilanjutkan untuk menemukan energi kinetik total, untuk pergerakan vertikal energi kinetik dari pusat massa balok adalah:

$$
E K_{\text {vertikal }}=\frac{1}{2} m \dot{y}^{2}
$$

Dimana $\dot{y}$ adalah kecepatan dari berat balok, dan persamaan untuk energi kinetik dari gerak torsi yaitu:

$$
E K_{\text {torsi }}=\frac{1}{6} m l^{2} \dot{\theta}
$$

Dimana $\dot{\theta}$ adalah kecepatan dari perubahan sudut.

Dengan demikian, energi kinetik total diberikan sebagai berikut:

$$
\begin{aligned}
& E K_{m}=E K_{\text {vertikal }}+E K_{\text {torsi }} \\
& E K_{m}=\frac{1}{2} m \dot{y}^{2}+\frac{1}{6} m l^{2} \dot{\theta}^{2} .
\end{aligned}
$$

Sekarang diperoleh Lagrangian sebagai berikut:

$$
\begin{aligned}
L= & E K_{m}-E P_{m} \\
L= & \frac{1}{2} m \dot{y}^{2}+\frac{1}{6} m l^{2} \dot{\theta}^{2}-\frac{K}{2}\left(\left[(y-l \sin (\theta))^{+}\right]^{2}+\right. \\
& {\left.\left[(y+l \sin (\theta))^{+}\right]^{2}\right)+m y g . }
\end{aligned}
$$

Berdasarkan pada asas least action, gerakan balok memenuhi persamaan Euler-Lagrange.

$$
\frac{d}{d t}\left(\frac{\partial L}{\partial \dot{\theta}}\right)-\frac{\partial L}{\partial \theta}=0 \quad \text { dan } \quad \frac{d}{d t}\left(\frac{\partial L}{\partial \dot{y}}\right)-\frac{\partial L}{\partial y}=0
$$

Hasil diperoleh dengan mengevaluasi turunan yang diperlukan pada persamaan Euler-Lagrange, menambahankan redaman $\delta_{1} \dot{\theta}$ dan dan $f(t)$, serta $\delta_{2} \dot{y}$. sehingga diperoleh:

$$
\left\{\begin{aligned}
\ddot{\theta}= & \frac{3 K}{m l} \cos (\theta)\left[(y-l \sin (\theta))^{+}-(y+l \sin (\theta))^{+}\right] \\
& -\delta_{1} \dot{\theta}+f(t) \\
\ddot{y}= & -\frac{K}{m}\left[(y-l \sin (\theta))^{+}+(y+l \sin (\theta))^{+}\right]-\delta_{2} \dot{y} \\
& +g
\end{aligned}\right.
$$

Sistem persamaan di atas merupakan model vibrasi dawai yang diusulkan oleh McKenna [4]

\section{PEMBAHASAN}

Model sudut defleksi pada skripsi ini adalah model yang menggambarkan gerak torsi dari balok yang digantung oleh dua buah dawai. Model yang menggambarkan sistem gerak ini adalah model McKenna. Sistem gerak yang digambarkan pada model McKenna adalah gerak vertikal pada dawai dan gerak torsi pada balok. Ilustrai sistem gerak dari model McKenna akan ditunjukkan pada Gambar 1.

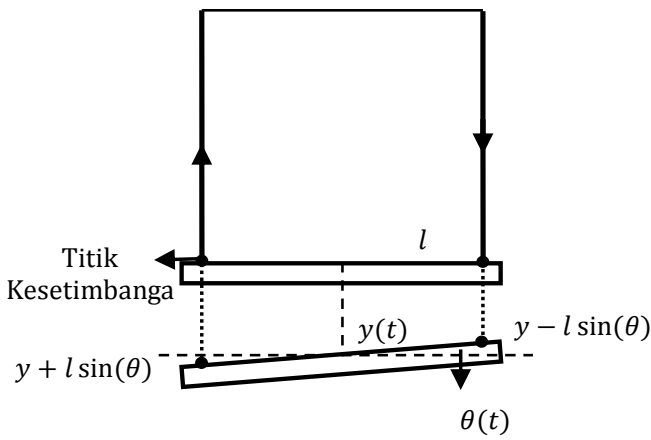

Gambar 1. Ilustrasi Model McKenna

Dengan mengasumsikan bahwa dawai tidak pernah kehilangan ketegangan, maka dimiliki $y \pm$ $l \sin (\theta) \geq 0 \quad$ dan $\quad(y \pm l \sin (\theta))^{+}=y \pm l \sin (\theta)$. Sehingga dengan mensubstitusikan $(y \pm$ $l \sin (\theta))^{+}=y \pm l \sin (\theta)$ pada sistem persamaan (9) dan setelah disederhanakan, maka diperoleh sistem persamaan diferensial sebagai berikut:

$\left\{\begin{array}{l}\ddot{\theta}=-\frac{3 K}{m} \sin (2 \theta)-\delta_{1} \dot{\theta}+f(t) \\ \ddot{y}=-\frac{2 K}{m} y-\delta_{2} \dot{y}+g\end{array}\right.$

Dengan $\quad f(t)=\beta \sin (\mu t) \quad$ berikut adalah persamaan sudut defleksi yang menggambarkan gerak torsi.

$\ddot{\theta}=-\frac{3 K}{m} \sin (2 \theta)-\delta \dot{\theta}+\beta \sin (\mu t)$ 
Misal : $\theta_{1}=\theta$ dan $\theta_{2}=\dot{\theta}$, dengan menurunkan $\theta_{1}$ dan $\theta_{2}$ terhadap $t$ maka akan diperoleh $\dot{\theta}_{1}=\dot{\theta}$ dan $\dot{\theta_{2}}=\ddot{\theta}$. Akibatnya persamaan (11) berubah menjadi sistem sebagai berikut:

$\left\{\begin{array}{l}\dot{\theta}_{1}=\theta_{2} \\ \dot{\theta}_{2}=-\frac{3 K}{m} \sin \left(2 \theta_{1}\right)-\delta \theta_{2}+\beta \sin (\mu t)\end{array}\right.$

Dari hasil perhitungan di atas diperoleh titik kesetimbangan $\left(\theta_{1}{ }^{*}, \theta_{2}{ }^{*}\right)=(n \pi, 0)$ dengan $n=$ $0,1,2,3, \ldots$ Untuk melakukan ekspansi Taylor cukup dibutuhkan satu titik kesetimbangan saja, maka dipilih $\left(\theta_{1}{ }^{*}, \theta_{2}{ }^{*}\right)=(0,0)$. Sehingga persamaan (12) menjadi:

$\left\{\begin{array}{l}\dot{\theta_{1}}=\theta_{2} \\ \dot{\theta_{2}}=-\frac{6 K}{m} \theta_{1}-\delta \theta_{2}+\beta \sin (\mu t)\end{array}\right.$

Untuk menentukan solusi dari sistem (13), terlebih dahulu diabaikan bentuk tak homogennya yaitu $\beta \sin (\mu t)$. Untuk menentukan solusi homogennya terlebih dahulu harus ditentukan nilai eigennya, yang diperoleh:

$$
\lambda_{1,2}=\frac{-\delta \pm \sqrt{\delta^{2}-\frac{24 K}{m}}}{2}
$$

Karena nilai $\delta^{2}-\frac{24 K}{m}$ dapat bernilai nol, positif, maupun negatif berakibat solusi homogen memiliki tiga kemungkinan berdasarkan nilai eigennya. Setelah diperoleh solusi homogennya dengan menggunakan metode variasi parameter maka diperoleh solusi sistem (13) sebagai berikut:

(a) Nilai eigen real berbeda, $\delta^{2}-\frac{24 K}{m}>0$

$$
\begin{array}{r}
\theta_{1}(t)=C_{1} e^{\frac{-\delta+P}{2} t}+C_{2} e^{\frac{-\delta-P}{2} t}+4 \beta \\
\left(\frac{\left(\delta^{2}-P^{2}-4 \mu^{2}\right) \sin (\mu t)-4 \mu \delta \cos (\mu t)}{\left(4 \mu^{2}+(\delta-P)^{2}\right)\left(4 \mu^{2}+(P+\delta)^{2}\right)}\right) \\
\theta_{2}(t)=C_{1} \frac{P-\delta}{2} e^{\frac{P-\delta}{2} t}+C_{2} \frac{-\delta-P}{2 e^{\frac{\delta+P}{2} t}}+4 \beta \\
\left(\frac{\left(\delta^{2}-P^{2}-4 \mu^{2}\right) \mu \cos (\mu t)+4 \delta \mu^{2} \sin (\mu t)}{\left(4 \mu^{2}+(\delta-P)^{2}\right)\left(4 \mu^{2}+(P+\delta)^{2}\right)}\right)
\end{array}
$$

$$
\begin{aligned}
& \text { dengan } P=\sqrt{\delta^{2}-\frac{24 K}{m}}, \text { dan } \\
& C_{1}=\frac{(P+\delta) \theta_{1}(0)+2 \theta_{2}(0)}{2 P}-
\end{aligned}
$$

$$
\frac{4 \beta \mu\left(\frac{24 K}{m}-4 \mu^{2}\right)+8 \beta \mu \delta(P-\delta)}{P\left(4 \mu^{2}+(\delta-P)^{2}\right)\left(4 \mu^{2}+(P+\delta)^{2}\right)}
$$

$C_{2}=-\frac{2 \theta_{2}(0)-(P-\delta) \theta_{1}(0)}{2 P}+$

$$
\frac{4 \beta \mu\left(\frac{24 K}{m}-4 \mu^{2}\right)+8 \beta \mu \delta(P-\delta)}{P\left(4 \mu^{2}+(\delta-P)^{2}\right)\left(4 \mu^{2}+(P+\delta)^{2}\right)}
$$

(b) Nilai eigen real kembar $\delta^{2}-\frac{24 K}{m}=0$

$$
\begin{gathered}
\theta_{1}(t)=e^{-\frac{\delta}{2} t}\left(C_{1}+C_{2}\right)+\frac{\beta t}{\mu^{2}+\frac{\delta^{2}}{4}}\left(\frac{\delta}{2} \sin (\mu t)-\mu \cos (\mu t)\right) \\
\beta\left(\frac{\left(4 \mu t\left(\delta^{2}+4 \mu^{2}\right)-16 \mu \delta\right) \cos (\mu t)}{\left(\delta^{2}+4 \mu^{2}\right)^{2}}-\right. \\
\left.\frac{\left(8 \mu^{2}(2+\delta t)+2 \delta^{3}(t-2)\right) \sin (\mu t)}{\left(\delta^{2}+4 \mu^{2}\right)^{2}}\right) \\
\theta_{2}(t)=e^{-\frac{\delta}{2} t}\left(\frac{-\delta}{2} C_{1}+\frac{2-\delta t}{2} C_{2}\right)+\beta \frac{2-\delta t}{2\left(\mu^{2}+\frac{\delta^{2}}{4}\right)} \\
\left(\frac{\delta}{2} \sin (\mu t)-\mu \cos (\mu t)\right)-\frac{\delta \beta}{2}\left(\frac{\left(4 \mu t\left(\delta^{2}+4 \mu^{2}\right)-16 \mu \delta\right)}{\left(\delta^{2}+4 \mu^{2}\right)^{2}}\right. \\
\left.\cos (\mu t)-\frac{\left(8 \mu^{2}(2+\delta t)+2 \delta^{3}(t-2)\right) \sin (\mu t)}{\left(\delta^{2}+4 \mu^{2}\right)^{2}}\right)
\end{gathered}
$$

dengan:

$$
\begin{aligned}
& C_{1}=\theta_{1}(0)+\left(\frac{16 \mu \delta}{\left(\delta^{2}+4 \mu^{2}\right)^{2}}\right) \beta \\
& \begin{aligned}
C_{2}=\theta_{2}(0)+\frac{\delta}{2} & \theta_{1}(0) \\
& \quad+\beta\left(\frac{4 \mu}{\delta^{2}+4 \mu^{2}}+\frac{8 \mu \delta^{2}}{\left(\delta^{2}+4 \mu^{2}\right)^{2}}\right)
\end{aligned}
\end{aligned}
$$

(c) Nilai eigen kompleks $\delta^{2}-\frac{24 K}{m}<0$

$$
\begin{gathered}
\theta_{1}(t)=e^{-\frac{\delta}{2} t}\left(C_{1} \cos \left(\frac{Q}{2} t\right)+C_{2} \sin \left(\frac{Q}{2} t\right)\right)+\frac{\beta \cos \left(\frac{Q}{2} t\right)}{Q} \\
\left(\frac{\frac{\delta}{2} \cos \left(\left(\frac{Q}{2}+\mu\right) t\right)+\left(\frac{Q}{2}+\mu\right) \sin \left(\left(\frac{Q}{2}+\mu\right) t\right)}{\left(\frac{\delta}{2}\right)^{2}+\left(\frac{Q}{2}+\mu\right)^{2}}-\right. \\
\left.\frac{\frac{\delta}{2} \cos \left(\left(\frac{Q}{2}-\mu\right) t\right)+\left(\frac{Q}{2}-\mu\right) \sin \left(\left(\frac{Q}{2}-\mu\right) t\right)}{\left(\frac{\delta}{2}\right)^{2}+\left(\frac{Q}{2}-\mu\right)^{2}}\right)+\frac{\beta}{Q} \\
\sin \left(\frac{Q t}{2}\right)\left(\frac{\frac{\delta}{2} \sin \left(\left(\frac{Q}{2}+\mu\right) t\right)-\left(\frac{Q}{2}+\mu\right) \cos \left(\left(\frac{Q}{2}+\mu\right) t\right)}{\left(\frac{\delta}{2}\right)^{2}+\left(\frac{Q}{2}+\mu\right)^{2}}\right.
\end{gathered}
$$




$$
\begin{gathered}
\left.-\frac{\frac{\delta}{2} \sin \left(\left(\frac{Q}{2}-\mu\right) t\right)-\left(\frac{Q}{2}-\mu\right) \cos \left(\left(\frac{Q}{2}-\mu\right) t\right)}{\left(\frac{\delta}{2}\right)^{2}+\left(\frac{Q}{2}-\mu\right)^{2}}\right) \\
\theta_{1}(t)=e^{-\frac{\delta}{2} t}\left(C_{1}\left(\frac{-\delta}{2} \cos \left(\frac{Q}{2} t\right)-\frac{Q}{2} \sin \left(\frac{Q}{2} t\right)\right)+C_{2}\right. \\
\left(\frac{-\delta}{2} \sin \left(\frac{Q}{2} t\right)+\frac{Q}{2} \cos \left(\frac{Q}{2} t\right)\right)+\frac{\beta}{Q}\left(\frac{-\delta}{2} \cos \left(\frac{Q}{2} t\right)-\right. \\
\left.\frac{Q}{2} \sin \left(\frac{Q t}{2}\right)\right)\left(\frac{\frac{\delta}{2} \cos \left(\frac{Q+2 \mu}{2} t\right)+\frac{Q+2 \mu}{2} \sin \left(\frac{Q+2 \mu}{2} t\right)}{\left(\frac{\delta}{2}\right)^{2}+\left(\frac{Q}{2}+\mu\right)^{2}}\right. \\
\left.\frac{\frac{\delta}{2} \cos \left(\frac{Q-2 \mu}{2} t\right)+\frac{Q-2 \mu}{2} \sin \left(\frac{Q-2 \mu}{2} t\right)}{\left(\frac{\delta}{2}\right)^{2}+\left(\frac{Q}{2}-\mu\right)^{2}}\right)+\frac{\beta}{Q}\left(\frac{-\delta}{2} \sin \left(\frac{Q}{2} t\right)\right. \\
\left.+\frac{Q}{2} \cos \left(\frac{Q}{2} t\right)\right)\left(\frac{\frac{\delta}{2} \sin \left(\frac{Q+2 \mu}{2} t\right)-\frac{Q+2 \mu}{2} \cos \left(\frac{Q+2 \mu}{2} t\right)}{\left(\frac{\delta}{2}\right)^{2}+\left(\frac{Q}{2}+\mu\right)^{2}}\right. \\
-\frac{\frac{\delta}{2} \sin \left(\left(\frac{Q}{2}-\mu\right) t\right)-\left(\frac{Q}{2}-\mu\right) \cos \left(\left(\frac{Q}{2}-\mu\right) t\right)}{\left(\frac{\delta}{2}\right)^{2}+\left(\frac{Q}{2}-\mu\right)^{2}}
\end{gathered}
$$

$$
\begin{aligned}
& \text { dengan } Q=\sqrt{\frac{24 K}{m}-\delta^{2}}, \\
& C_{1}=\theta_{1}(0)-\frac{\beta}{Q}\left(\frac{2 \delta}{\delta^{2}+(Q+2 \mu)^{2}}-\frac{2 \delta}{\delta^{2}+(Q-2 \mu)^{2}}\right) \\
& C_{2}=\frac{2 \theta_{2}(0)+\delta \theta_{1}(0)}{Q}-\frac{\beta}{Q^{2}}\left(\frac{2 Q^{2}+4 \mu Q}{\delta^{2}+(Q+2 \mu)^{2}}-\right. \\
& \left.\quad \frac{2 Q^{2}-4 \mu Q}{\delta^{2}+(Q-2 \mu)^{2}}\right)
\end{aligned}
$$

Untuk melihat perilaku dari model sudut defleksi diberikan parameter-parameter sebagai berikut:

Tabel 1. Daftar Parameter

\begin{tabular}{cll}
\hline SIMBOL & \multicolumn{3}{c}{ KETERANGAN } \\
\hline$m$ & Massa per satuan panjang balok \\
& $\left(\mathrm{Kgs}^{2} / \mathrm{m}\right) m=657,3$ \\
$K$ & Konstanta spring $(\mathrm{Kg} / \mathrm{m}), K=3,75$ \\
$l$ & Panjang balok $l=60$ \\
$\delta$ & viscous dumping bernilai 0,01 \\
$\mu$ & Konstanta antara 1,2 sampai 1,6 \\
$\beta$ & Amplitudo berkisar antara 0,02 sampai \\
& 0,06
\end{tabular}

Sumber: Data fiktif, hanya untuk ilustrasi

Dari data yang diberikan dapat diketahui solusi mana yang akan digunakan dengan cara, subtitusikan parameter ke dalam persamaan berikut $\delta^{2}-\frac{24 K}{m}$, diperoleh $\delta^{2}-\frac{24 K}{m}<0$. Sehingga solusi yang digunakan adalah persamaan (16). Dengan mensubstitusikan parameter- parameter dari Tabel 1 ke persamaan (16) maka diperoleh grafik sebagai berikut:

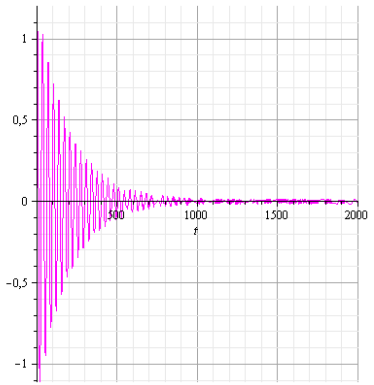

(a)

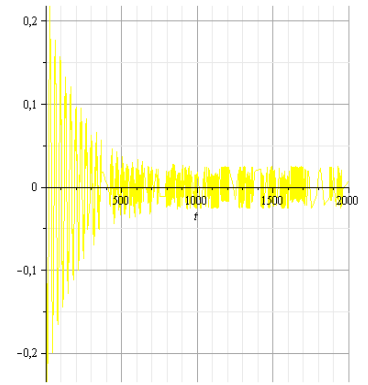

(b)
Gambar 2. (a) Grafik Solusi $\theta_{1}(t)$

(b) Grafik Solusi $\theta_{2}(t)$

Untuk melihat pengaruh faktor eksternal $f(t)$ berikut ditunjukkan grafik solusi bentuk homogennya tanpa faktor eksternal.

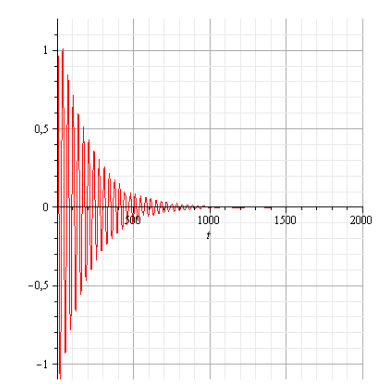

Gambar 3. Grafik Solusi $\theta_{1}$

Adapun perilaku dari model dapat dilihat pada medan vektor dan trayekori sebagai berikut:

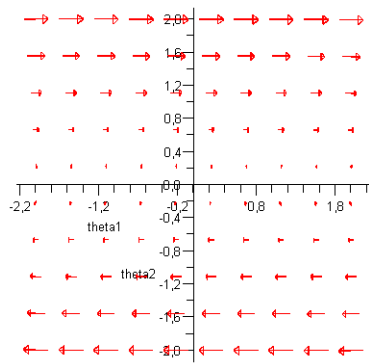

(a)

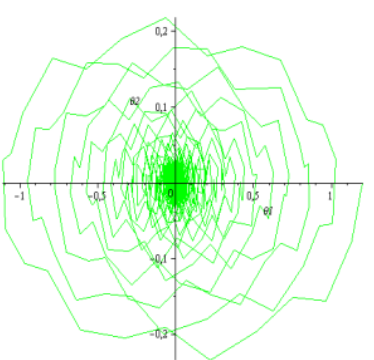

(b)
Gambar 4. (a) Medan Vektor Model Sudut Defleksi (b)Trayektori Solusi $\theta_{1}(t)$ dan $\theta_{2}(t)$

Dari Gambar 5 dan Gambar 6 menunjukkan bahwa model sudut defleksi tidak stabil, diketahui model sebelum ditambah faktor eksternal memiliki kestabilan jenis spiral sink artinya stabil asimtotik, dan setelah ditambah faktor eksternal menjadikan model sudut defleksi menjadi tidak stabil. 


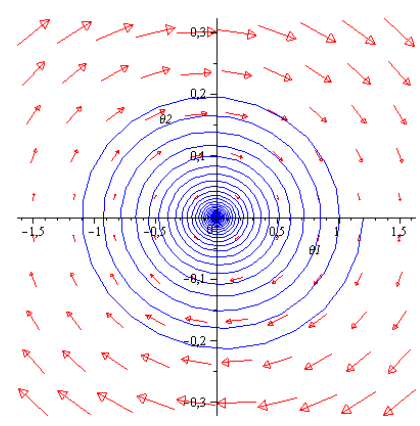

Gambar 5. Potret Fase Model Sudut Defleksi Sebelum Ditambah

\section{KESIMPULAN}

Faktor eksternal $f(t)$ memiliki dampak yang besar terhadap kestabilan model sudut defleksi. Model sudut defleksi tanpa faktor eksternal selalu stabil, tetapi, jika ditambah dengan faktor eksternal grafik solusi menjadi sangat fluktuatif di sekitar titik tetap dan potret fase menunjukkan bentuk yang sangat tidak beraturan atau bersifat chaotic.

Untuk mendapatkan interpretasi yang lebih baik perlu dilakukan analisis kembali dengan memperhatikan gaya yang terjadi pada dawai yaitu $K(y \pm l \sin (\theta))^{+}$.

\section{REFERENCES}

[1] G. Vries, T. Hillen, M. Lewis, J. Müller and M. Schönfisch, A Course in Mathematical Biology: Quantitative Modeling with Mathematical and Computational Methods, Alberta: SIAM, 2006.

[2] A. G. Parlos, "Linearization Of Nonlinear Dynamics," 2014. [Online]. Available: http://parlos.tamu.edu/MEEN651/Lineariza tion.pdf. [Accessed 17 Agustus 2014].

[3] R. C. Robinson, An Introduction Dynamical System Continuous and Discrete, New Jersey: Pearson Education, 2004.

[4] W. E. Boyce and R. C. DiPrima, Elementary Differential Equations and Boundary Value Problems, New York: John Wiley \& Sons, Inc, 2009.

[5] R. 0. Kwofie, "A mathematical model of a suspension bridge - case study: Adomi bridge, Atimpoku, Ghana," Global Advanced Research Journal of Engineering, Technology, and Innovation, vol. 1(3), pp. 047-062, 2012. 